\title{
GAMBARAN SISTEM PENGELOLAAN RANTAI DINGIN VAKSIN DI BEBERAPA PUSKESMAS KECAMATAN DI WILAYAH JAKARTA TIMUR TAHUN 2019
}

\section{DESCRIPTION OF CAKIN COLD CHAIN MANAGEMENT SYSTEM IN SOME PUSKESMAS KECAMATAN IN JAKARTA TIMUR REGION IN 2019}

\author{
Ariyanti Kusumadewi ${ }^{1}$, Astri Dwi Lestari ${ }^{2}$ \\ Akademi Farmasi Mahadhika, \\ Jl. Suci 9A, Susukan - Ciracas Jakarta Timur 137150
}

Summited : 05 Februari 2020 Reviewed : 29 Maret 2020

Accepted : 31 Maret 2020

\begin{abstract}
ABSTRAK
Pengelolaan vaksin merupakan bagian dari kualitas vaksin yang dapat mencegah terjadinya penyimpangan dalam penyimpanan maupun pendistribusian vaksin agar potensi vaksin tetap terjagasaat akan digunakan. Dalam penelitian ini akan diketahui sistem pengelolaan rantai dingin vaksin di beberapa puskesmas kecamatan di wilayah Jakarta Timur bulan Juli tahun 2019.Penelitian ini merupakan penelitian kualitatif. Pengambilan sampel dilakukan dengan menggunakan teknik purposive sampling.Sumber data primer diambil dengan wawancara mendalam dan data sekunder berasal dari telaah dokumen serta observasi data tahun 2019.Pada penelitian ini semua petugas telahmengikutipelatihan minimal satu kali dan memiliki tingkat pendidikan pada jenjang perguruan tinggi. Semua pendistribusian vaksin telah menggunakan cold box dancold pack. Semua vaksin diletakkan dalam vaccine carrier berisi cool pack dan termometer, semua vaksin heat sensitive disusun dekat evaporator dan vaksin freeze sensitive disusun menjauhi evaporator, semua lemari es di puskesmas tersebut hanya khusus menyimpan vaksin, dan dilengkapi termometer yang berada di luar dan di dalam lemari es, semua puskesmas selalu memantau suhu secara rutin dua kali sehari, melakukan pemilihan vaksin yang di dasarkan pada prinsip FEFO dan pertimbangan VVM, dan menyediakan formulir pencatatan suhu dan Standard Operasional Procedure (SOP) di masing-masing instansi, serta mengatur jarak minimal antara lemari es/freezer dan dinding belakang dan mengatur jarak minimal antara lemari es/freezer dengan lemari es/freezer lainnya serta pada bagian bawah lemari es diletakkan cold pack sebagai penahan dingin dan kestabilan suhu. Pengelolaaan rantai dingin vaksin di lima puskesmas kecamatan Jakarta Timur telah sesuai dengan pedoman Vaccine Storage and HandlingToolkit(CDC 2014).
\end{abstract}

Kata kunci : vaksin, puskesmas, rantai dingin vaksin.

\begin{abstract}
Vaccine management is a part of vaccine quality that can be used to prevent irregularities in vaccine storage and distribution so that the vaccine's potential is maintained when it is to be used. This research will discuss the cold vaccine management system in several subdistrict health centers in East Jakarta in July 2019. This research is a qualitative study. Sampling is done by using purposive sampling technique. Primary data sources were taken by in-depth interviews and secondary data obtained from document review and
\end{abstract}


observation of 2019 data. In this study all officers had attended training at least once and had education at the tertiary level. All vaccine distributions have used cold boxes and cold packs. All vaccines are placed in vaccine carriers containing cool packs and thermometers, all heatsensitive vaccines are prepared near the evaporator and freeze-sensitive vaccines are arranged away from the evaporator, all the refrigerators in this puskesmas only store vaccines specifically, and are equipped with thermometers that are outside and inside the refrigerator, all puskesmas, every day, choose vaccines based on FEFO and VVM considerations, and provide a temperature recording form and Standard Operating Procedure (SOP) at each institution, and each minimum distance between the refrigerator / freezer and the back wall and put a minimum distance between the refrigerator / freezer with other refrigerators / freezers as well as at the bottom of the refrigerator placed a cold package as a barrier to cold and temperature stability. The management of cold vaccines in five health centers in East Jakarta sub-district has been in accordance with the guidelines for Vaccine Storage and Handling Equipment (CDC 2014).

Keywords: vaccines, puskesmas, cold chain vaccines.

\section{Penulis Korespondensi :}

Ariyanti Kusumadewi

Akademi Farmasi Mahadhika Jl. Suci 9A, Susukan - Ciracas Jakarta Timur

Email: ariyantikusumadewi@gmail.com Hp 081289473704

\section{PENDAHULUAN}

Penyakit menular masih menjadi masalah kesehatan di Indonesia. Salah satu tindakan pencegahan yang terbukti sangat cost effective adalah imunisasi. Imunisasi bertujuan untuk menurunkan angka kesakitan, kecacatan, dan kematian akibat Penyakit yang Dapat Dicegah Dengan Imunisasi (PD3I). Menurut Undang-Undang Nomor 36 Tahun 2009 tentang Kesehatan, imunisasi merupakan salah satu upaya untuk mencegah terjadinya penyakit menular yang merupakan salah satu kegiatan prioritas kementerian kesehatan sebagai salah satu bentuk nyata komitmen pemerintah untuk mencapai Millennium Development Goals (MDGs) khususnya untuk menurunkan angka kematian pada anak. (Litalien et al., 2009)

Data dari Direktorat Pencegahan dan Pengendalian Penyakit, Kementerian Kesehatan (Kemenkes) RI menunjukkan sejak 2014-2016, terhitung sekitar 1,7 juta anak belum mendapatkan imunisasi atau belum lengkap status imunisasinya. Namun demikian, cakupan imunisasi dasar lengkap di Indonesia pada 2015 hingga 2017 mengalami peningkatan. Berdasarkan data dari Direktorat Jenderal Pencegahan dan Pengendalian Penyakit, Kemenkes RI, pada 2015 cakupan imunisasi secara nasional mencapai 86,5\%, pada 2016 mencapai 91,6\%, dan pada 2017 mencapai 92,4\%. Data dari Riskesdas 2018 menunjukkan bahwa cakupan proporsi imunisasi dasar di Indonesia pada anak umur 12-23 bulan mencapai $83.1 \%$ dan cakupan proporsi imunisasi lanjutan mencapai $57.9 \%$. Sebagaimana tercantum dalam Permenkes No. 12 Tahun 2017, cakupan Imunisasi haruslah dipertahankan tinggi dan merata. Cakupan yang tinggi tentunya didukung oleh pelayanan imunisasi yang berkualitas dan proses penyimpanan dan penanganan vaksin yang baik karena vaksin akan mudah hilang potensinya apabila tidak disimpan pada temperatur yang sesuai, sehingga kualitas manajemen rantai dingin akan berbanding lurus dengan kualitas vaksin itu sendiri (Magee et al., 2017).

Kebehasilan imunisasi tergantung oleh beberapa faktor yaitu status imun penjamu, faktor genetik penjamu, dan kualitas serta kuantitas vaksin. Salah satu faktor yang mempengaruhi keberhasilan imunisasi adalah kualitas vaksin yang digunakan. Penyimpanan dan transportasi vaksin harus memenuhi syarat rantai dingin vaksin yang baik untuk mempertahankan kualitas vaksin. Kualitas vaksin yang rendah menyebabkan vaksin tidak poten sehingga tidak dapat memberikan perlindungan.(Ranuh et al., 2017) Rantai dingin 
adalah rantai pasokan dengan suhu yang terkontrol mencakup semua peralatan dan prosedur terkait vaksin. Rantai dingin dimulai dengan unit penyimpanan dingin di pabrik, transportasi, pengiriman vaksin, penyimpanan yang benar di fasilitas penyedia, dan berakhir dengan pemberian vaksin kepada pasien.(CDC, 2019)(Chiappin et al., 2014)

Hasil penelitian yang dilakukan pada tahun 2011 dan 2012 menunjukkan bahwa banyak terjadi kerusakan vaksin saat pengelolaan karena peralatan tidak dikelola dengan baik. (Ministry of Health Indonesia, 2013)Oleh sebab itu pemerintah mulai menyediakan lemari es penyimpan vaksin sampai dengan akhir 2016 , sudah $78,8 \%$ puskesmas memiliki lemari es penyimpan vaksin yang sesuai standar. Sementara itu, pada tahun 2017 disediakan lagi 1.861 buah lemari es, yang saat ini dalam proses pendistribusian dan pemasangan di fasilitas kesehatan di daerah. Rencananya pada tahun 2018 akan disediakan lagi sebanyak 1.045 buah, sehingga, pada akhir tahun 2018, Kementerian Kesehatan memastikan ketersediaan rantai dingin di semua puskesmas dapat terpenuhi untuk mendukung pelaksanaan program imunisasi, yakni 9.951 puskesmas akan memiliki rantai dingin vaksin sesuai standar. Saat ini, sudah $92,2 \%$ atau lebih kurang sebanyak 9.800 puskesmas yang sudah memiliki rantai dingin terstandar. Kementerian Kesehatan, Dinkes Provinsi, Dinkes Kabupaten/Kota, serta Puskesmas perlu bersama-sama berkomitmen dalam menerapkan manajemen rantai dingin yang berkualitas untuk meminimalisir kesalahan yang berpotensi terjadi di berbagai titik penanganan vaksin (Permenkes 12, tahun 2007). Penyimpanan vaksin membutuhkan suatu perhatian khusus karena vaksin merupakan sediaan biologis yang rentan terhadap perubahan temperatur lingkungan. Di dalam Permenkes Nomor 12 tahun 2017 tentang Penyelenggaraan Imunisasi disebutkan bahwa vaksin merupakan produk biologis yang mudah rusak sehingga harus disimpan pada suhu tertentu, yakni pada suhu $2 \mathrm{s.d} 8^{\circ} \mathrm{C}$ untuk vaksin sensitif beku (tidak boleh beku), dan pada suhu -15 s.d $-25{ }^{\circ} \mathrm{C}$ untuk vaksin yang sensitif panas, hanya vaksin polio yang masih memerlukan tempat penyimpanan dengan suhu dibawah $0^{\circ} \mathrm{C}$. Sejumlah vaksin, seperti Hepatitis B, DPT-HB-Hib, IPV, DT, Td akan berpotensi menjadi rusak jika terpapar suhu beku. Sedangkan vaksin Polio, BCG, dan Campak akan berpotensi rusak jika terpapar suhu panas. Namun secara umum, vaksin akan rusak jika terpapar oleh sinar matahari secara langsung (Magee et al., 2017).

Studi yang dilakukan oleh Kairul dkk (2016) mengenai Gambaran Pengelolaaan Rantai Dingin Vaksin Program Imunisasi Dasar di 12 Puskesmas di Sorolangun menunjukkan bahwa pengelolaan rantai dingin vaksin belum sesuai dengan Peraturan Menteri Kesehatan No 42 tahun 2013 tentang Penyelenggaraan imunisasi. (Kairul, Udiyono and Saraswati, 2016)dan studiyang dilakukan oleh Debby (2018) mengenai Evaluasi Implementasi Managemen Rantai Dingin Vaksin dengan Viabilitas Vaksin di Suku Dinas Kesehatan Jakarta Timur dan jajarannya menunjukkan bahwa implementasi managemen rantai dingin vaksin di dinas kesehatan provinsi, sudinkes Jakarta Timur, serta 10 puskesmas kecamatan sudah cukup baik, tapi perlu dimaksimalkan terutama dalam pemantauan suhu, revisi SOP rutin dan monitoring evaluasi ke puskesmas kelurahan serta faskes swasta (Debby Permatasari Iwan Dwiprahasto, no date).

Tujuan penelitian ini adalah mengetahui sistem pengelolaan rantai dingin vaksin yang mencakup kualifikasi petugas pendistribusian, dan penyimpanan di beberapa puskesmas kecamatan di wilayah Jakarta Timur tahun 2019.

\section{METODE PENELITIAN \\ Jenis Penelitian}

Penelitian ini merupakan penelitian kualitatif. Pengambilan sampel dilakukan dengan menggunakan teknik purposive sampling. Penelitian ini dilakukan di lima Puskesmas Kecamatan Jakarta Timur. Penelitian ini menggunakan sumber data primer dan sekunder. Sumber data primer diambil dengan wawancara mendalamsedangkan data sekunder berasal dari telaah dokumen serta observasi data tahun 2019. 


\section{Variabel Penelitian}

Variabel penelitian ini lebihditujukan kepada variabel yangdianggap berpengaruh terhadapkualitas pengelolaan rantai dinginvaksin, indikator tersebut adalahtingkat pendidikan pengelola vaksin, pelatihan pengelola vaksin,dan pengetahuan petugas pengelola vaksin, ketersediaan termometer pada lemari es beserta dokumen catatan dan grafik suhu, distribusi vaksin harus menggunakan cold box untuk vaksin TT,DT, dan Hepatitis B, distribusi vaksin harus menggunakan cold pack untuk vaksin BCG, Polio, Campak, ketersediaan pedoman pengelolaan vaksin, prosedur perlengkapan saat membawa vaksin dari provinsi (kota) atau kabupaten ke puskesmas, jarak minimal antara lemari es/freezer dan dinding belakang adalah $10-15 \mathrm{~cm}$ atau sampai pintu lemari es/freezer dapat dibuka, jarak minimal antara lemari es/freezer dengan lemari es/freezer lainnya adalah $\pm 15 \mathrm{~cm}$, ketersediaan bagian bawah lemari es diletakkan cold pack sebagai penahan dingin dan kestabilan suhu, vaksin heat sensitif diletakkan di rak atas dan vaksin freeze sensitif diletakkan di rak bawah, lemari es khusus menyimpan vaksin, pemilihan vaksin didasarkan pada prinsip FEFO dan pertimbangan VVM, pemantauan suhu dipantau secara rutin sehari dua kali.

\section{Lokasi dan Waktu Penelitian}

Lokasi penelitian ini dilaksanakan di lima puskesmas kecamatan di wilayah Jakarta Timur, yaitu puskesmas kecamatan Kramat Jati, Ciracas, Makassar, Pasar Rebo, dan Duren Sawit.Waktu penelitian ini dilaksanakan bulan Juli tahun 2019.

\section{Populasi dan Sampel}

Populasi pada penelitian ini adalah puskesmas kecamatan yang ada di wilayah Jakarta Timur sebanyak 10 Puskesmas Kecamatan.Teknik sampling yang digunakan yaitu dengan metode Non Probability Sampling (Quota Sampling).

\section{HASIL DAN PEMBAHASAN}

\section{Variabel Petugas Pengelola Rantai Dingin Vaksin}

Di lima puskesmas kecamatanyang diteliti, semua petugas rantai dingin vaksin merupakan tamatan perguruan tinggi dan telah mengikuti pelatihan atau sharing knowledge rantai dingin vaksin yang dilaksanakan oleh Kemenkes atau Suku Dinas yang dilakukan minimal 6 bulan sekali (Lihat tabel I). Petugas rantai dingin vaksin juga harus mampu menjawab sejumlah pertanyaan tentang prinsip-prinsip pengelolaan vaksin dengan baik.Personil menjadi salah satu komponen penting pada sistem rantai dingin. Personil yang dimaksud adalah seseorang yang bertanggungjawab penuh terhadap rantai dingin vaksin karena pengelolaan vaksin yang baik di tingkat puskesmas memiliki hubungan erat dengan petugas yang mendapatkan pelatihan secara berkala guna menjaga kinerja petugas tersebut.

Seperti halnya penelitian yang dilakukan oleh Nadia Rahmah, dkk yang berjudul Hubungan Karakteristik dan Tingkat Pengetahuan Petugas Imunisasi terhadap Praktik Penyimpanan dan Transportasi Vaksin Imunisasi di Tingkat Puskesmas Kota Padang Tahun 2014 didapatkan kesimpulan terdapatnya hubungan bermakna antara pengetahuan petugas dengan praktik penyimpanan dan transportasi vaksin di Puskesmas Kota Padang sehingga diperlukan petugas pengelolaan rantai dingin vaksin di layanan primer harus memiliki pengetahuan dan pemahaman yang baik mengenai transportasi dan penyimpanan vaksin.(Rahmah and Lasmini, 2014) Penelitian serupa juga pernah dilakukan oleh Noer Endah Pracoyo, dkkyang berjudul Hubungan Antara Pengetahuan dan Sikap Pengelola Vaksin Dengan Skor Pengelolaan Vaksin Didaerah Kasus Difteri Jawa Timur didapatkan kesimpulan pelatihan petugas dalam mengelola vaksin berpengaruh terhadap ketepatan dalam pengelolaan vaksin di tempat pelayanan kesehatan (Knowledge et al., 2013).

\section{Variabel Pendistribusian Rantai Dingin Vaksin}

Berdasarkan data hasil penelitian di lima puskesmas kecamatan di wilayah Jakarta Timur telah sesuai dengan pedoman Vaccine Storage and Handling Toolkit (CDC 2014) 
dalam hal pendisribusian vaksin. (Lihat tabel I)Menurut hasil observasidi PKM A, B, C, D, dan E sudah tersedia cold box, cold pack dan vaccine carrieruntuk proses pendistribusian vaksin agar suhu vaksin tetap sesuai yang dipersyaratkan.

Vaksin diambil dari suku dinas sebulan sekali yang permintaannya disesuaikan dengan kebutuhan. Vaksin tersebut diambil dengan menggunakan cold box yang dilengkapi cold pack dan termometer di dalamnya untuk memastikan suhu vaksin tetap terjaga dalam kondisi stabil sampai dengan pendistribusian selanjutnya ke puskesmas kelurahan, dan klinik mandiri.Cold box adalah alat untuk menyimpan sementara vaksin yang diambil dari suku dinas kesehatan Jakarta Timur yang didalamnya dilengkapi cold pack dan termometersedangkan cold pack sendiri sudah dibekukan di dalam freezer selama 24 jam. Dalam pendistribusian vaksin hal yang perlu diperhatikan adalah kondisi VVM, tanggal kadaluarsa FEFO, dan urutan masuk vaksin FIFO. Setiap distribusi juga menggunakan cold box yang berisi cool pack untuk vaksin sensitif beku serta cold pack untuk vaksin sensitif panas dan pengepakan vaksin harus dilengkapi dengan indikator pembekuan. Dalam hal ini vaccine carrier juga dilengkapi dengan cool pack dan termometer untuk mengontrol suhu saat membawa vaksin dari puskesmas kecamatan hingga ke puskesmas kelurahan, KIA, dan klinik bidan mandiri.

Pada beberapa penelitian yang sudah pernah dilakukan mengenai pengelolaan rantai dingin masih belum optimal sehingga akan mempengaruhi kualitas vaksin dan berdampak pada kualitas mutu pelayanan imunisasi. Salah satunya penelitian yang pernah dilakukan oleh Tri Dewi Kristini yang berjudul Faktor-Faktor Risiko Kualitas Pengelolaan Vaksin yang Buruk Di Unit Pelayanan Swasta (Studi Kasus di Kota Semarang) memberikan hasil kesimpulan bahwa adanya faktor risiko yang berpengaruh terhadap kualitas pengelolaan vaksin meliputi seperti tidak tersedia pedoman, pengetahuan petugas yang kurang, fungsi lemari es tidak khususmenyimpan vaksin, tidak tersedia termometer, cara membawa vaksin yang salah dan komitmenpetugas sekaligus pemilik unit pelayanan kesehatan yang kurang(Kristini, 2008) dan penelitian serupa juga pernah dilakukan oleh Gebbie Prisiliya Lumentut, dkk yang berjudul Evaluasi Penyimpanan dan Pendistribusian Vaksin Dari Dinas Kesehatan Kota Manado Ke Puskesmas Tuminting, Puskesmas Paniki Bawah dan Puskesmas Wenang didapatkan kesimpulan bahwa Dinas Kesehatan Kota Manado ke puskesmas Tuminting, puskesmas Paniki Bawah dan puskesmas Wenang belum sesuai dengan pedoman pengelolaan cold chain dalam hal penyimpanan dan pendistribusian vaksin yang terlihat dari tidak adanya alat pengukur suhu, freeze tag, tidak memiliki genset, tidak memiliki indikator pembeku dan terbatasnya kotak dingin cair dalam kotak dingin selama pendistribusian(Gebbie Prisiliya Lumentut, Nancy C. Pelealu, 2015) serta penelitian serupa yang juga dilakukan oleh Kairul, Ari Udiyonoyang berjudul Gambaran Pengelolaan Rantai Dingin Vaksin Program Imunisasi Dasar (Studi di 12 Puskesmas Induk Kabupaten Sarolangun) didapatkan kesimpulan bahwa tidak adanya pengelolaan vaksin program imunisasi Dasar di 12 Puskesmas Induk Kabupaten Sarolangun sesuai dengan PeraturanMenteri Kesehatan No 42 tahun 2013 tentang Penyelenggaraan imunisasi (Kairul, Udiyono and Saraswati, 2016)dan penelitian yang dilakukan oleh Gantinia, dkk yang berjudul Gambaran Penerapan Rantai Dingin Vaksin Imunisasi Dasar di Purwakarta Tahun 2017 memberikan kesimpulan bahwa ketersediaan peralatan dan penerapan rantai dingin vaksin imunisasi dasar oleh koordinator imunisasi di puskesmas kabupaten Purwakarta masih belum optimal dalam segi kualitas dan kuantitas (Utoro, Masria and Trisnadi, 2017).

\section{Variabel Penyimpanan Rantai Dingin Vaksin}

Penyimpanan dilakukan untuk menjaga kualitas vaksin tetap baik sejak diterima sampai didistribusikan ketingkat berikutnya atau digunakan ke pasien dan harus disimpan pada suhu yang telah ditetapkan. Sebagaimana disebutkan dalam Peraturan Menteri Kesehatan Nomor 42 Tahun 2013, pemerintah daerah provinsi dan pemerintah daerah kabupaten/kota bertanggungjawab terhadap penyediaan unit logistik imunisasi untuk menyimpan vaksin dan logistik imunisasi lainnya pada instalasi farmasi yang memenuhi standar dan persyaratan teknis penyimpanan (Ministry of Health Indonesia, 2013). Suhu 
adalah faktor yang sangat penting dalam proses penyimpanan vaksin karena dapat menurunkan potensi vaksin yang bersangkutan apabila disimpan pada suhu yang tidak sesuai. Penyimpanan vaksin pada suhu yang berubah-ubah akan menyebabkan penurunan potensi yang cukup besar. Penyimpanan vaksin yang sesuai menurut Peraturan Menteri Kesehatan Nomor 42 Tahun 2013 yaitu penyimpanan vaksin heat sensitive seperti polio, $\mathrm{BCG}$, dan campak disimpan pada suhu $-15^{\circ} \mathrm{C}$ sampai dengan $-25^{\circ} \mathrm{C}$ sedangkan vaksin freeze sensitive seperti DPT, DT, dT, HB, dan Hib disimpan pada suhu $2-8^{\circ} \mathrm{C}$. (Ministry of Health Indonesia, 2013)Pemilihan vaksin yang akan digunakan kepada pasien didasarkan pada prinsip First Expire First Out (FEFO) tetapi dengan mempertimbangkan kondisi VVM yang berarti barang yang tanggal expire lebih dekat maka harus digunakan terlebih dahulu serta pertimbangan VVM dimana vaksin yang telah mendapatkan paparan panas lebih banyak (dengan perubahan kondisi VVM A ke kondisi VVM B) harus digunakan terlebih dahulu meskipun masa kadaluarsanya masih lebih panjang, dan vaksin dengan kondisi VVM C dan D tidak boleh digunakan karena vaksin telah rusak.Pemantauan suhu penyimpanan vaksinsangat penting dalam menetapkan secaracepat apakah vaksin masih layakdigunakan atau tidak, dengan cara selalumemperhatikan vaccine vial monitor (VVM) yang ada pada setiap masing-masing vaksin untuk mengetahui apakah vaksin masih layak untuk digunakan (CDC, 2019).

Paparan panas harus dihindari dalam proses penyimpanan vaksin, dikarenakan sifat vaksin yang akan berubah jika terkena paparan panas. Vaksin dapat mengalami kerusakan hingga kehilangan potensi jikaterpapar oleh panas. Terdapat indikator paparan panas yang melekat pada vial vaksin yang digunakan pada program imunisasi telah dilengkapi dengan VVM. VVM tidak dapat mengukur potensi vaksin secara langsung, namun VVM dapat memberikan informasi kelayakan penggunaan vaksin yang telah terpapar panas. VVM memiliki karakteristik khusus untuk setiap jenis vaksin. VVM tidak dapat digunakan untuk jenis vaksin yang berbeda. Contohnya, VVM untuk vaksin polio tidak dapat digunakan untuk vaksin DPT dan juga sebaliknya. Pada aspek pemilihan vaksin yang akan digunakan untuk diberikan kepada pasien, pemilihan vaksin di PKM A didasarkan pada prinsip First Expire First Out (FEFO) tetapi dengan mempertimbangkan kondisi VVM.Setelah dilakukan observasi di PKM A jarak antara refrigerator dengan dinding belakang dan refrigerator lainnya sekitar $10-15 \mathrm{~cm}$ sehingga sirkulasi udara disekitar menjadi baik serta terlindung sinar matahari langsung. Hasil observasi dan wawancara yang dilakukan di PKM A menunjukkan bahwa monitoring suhu lemari es dan ruangan dilakukan dengan baik oleh petugas vaksin dengan melakukan pencatatan suhu sebanyak dua kali sehari setiap pagi dan sore.

Pencatatan suhu pada hari libur dilakukan oleh petugas yang bertugas pada hari tersebut. Pada PKM A juga telah dilengkapi dengan termometer dan freeze tag didalamnya serta peruntukkan lemari es khusus untuk vaksin dan tidak ditemukan benda lain di dalam lemari es. Jarak antara refrigerator dan dinding belakang juga sudah sesuai dengan pedoman yaitu antara $10-15 \mathrm{~cm}$ atau sampai pintu lemari freezer dapat dibuka. Hasil observasi juga telah dilakukan di PKM B menunjukkan bahwa monitoring suhu vaksin dilakukan oleh petugas rantai dingin vaksin dengan adanya grafik pencatatan suhu vaksin yang dilakukan dua kali sehari setiap pagi dan sore dan dihari libur dilakukan oleh petugas yang dinas di hari tersebut. Pada lemari es juga menunjukkan kondisi penyimpanan lemari es yang dilengkapi dengan termometer dan freeze tag dengan jarak minimal antara vaksin satu dengan yang lain $1-2 \mathrm{~cm}$. Freeze tag merupakan indikator paparan suhu dingin. Apabila terpapar suhu $0^{\circ} \mathrm{C}$ selama 60 menit, maka tanda $(\sqrt{ })$ akan berubah menjadi tanda $(X)$. Freeze tag ditempatkan pada penyimpanan vaksin yang peka terhadap pembekuan. Apabila pada freeze tag didapatkan tanda (X), maka harus dilakukan shake test pada vaksin DT, DPT, Hepatitis B dan DPTHB/HIB. Freeze tag yang tidak dapat memantau suhu beku maka harus segera diganti.

Pemilihan vaksin untuk didistribusikan di PKM B juga didasarkan dengan prinsip FEFO dengan tetap mempertimbangkan kondisi VVM. Monitoring suhu harus dilakukan untuk mengecek ada tidaknya kerusakan pada vial vaksin. Hasil observasi yang dilakukan di 
PKM C bahwa monitoring suhu dilakukan dua kali sehari pagi dan sore oleh petugas vaksin, dan di hari libur dilakukan oleh petugas yang bertugas di hari tersebut.Berdasarkan observasi yang telah dilakukan di PKM C, jarak antara refrigerator dengan dinding belakang dan refrigerator lainnya telah sesuai dengan pedoman yaitu $10-15 \mathrm{~cm}$. Hasil observasi yang telah dilakukan di PKM C menunjukkan kondisi penyimpanan vaksin telah sesuai pedoman Vaccine Storage and HandlingToolkit(CDC 2014)dimana vaksin heat sensitive diletakkan di rak atas dan vaksin freeze sensitive diletakkan di rak bawah. Pada pemilihan vaksin yang akan didistribusikan di PKM $\mathrm{C}$ juga memperhatikan prinsip FEFO dengan mempertimbangkan kondisi VVM.

Hasil observasi yang dilakukan di PKM D juga menunjukkan bahwa ruang penyimpanan vaksin yang luas membuat penempatan jarak refrigerator dengan dinding belakang terjaga sirkulasi udara disekitarnya tetap baik.Monitoring suhu di PKM D juga dilakukan oleh petugas penanggung jawab rantai dingin vaksin secara rutin dua kali sehari setiap pagi dan sore dan dihari libur dilakukan oleh petugas yang bertugas di hari tesebut untuk memastikan suhu vaksin dalam kondisi baik. Pada PKM D terdapat vial dengan kondisi VVM B. Vial vaksin dengan kondisi VVM B ini harus digunakan dahulu sebelum vaksin rusak atau ke kondisiVVM C walaupun tanggal expire masih lebih jauh. Jarak penyimpanan antar kotak vaksin didalam chiller dan freezer yang direkomendasikan dalam pedoman Vaccine Storage and HandlingToolkit(CDC 2014)adalah sekitar 1-2 cm. Jarak antar kotak membuat penyimpanan tidak terlalu padat sehingga sirkulasi udara dapat dijaga. Pemberian jarak bertujuan untuk meningkatkan sirkulasi udara dingin disekitar vaksin. Sirkulasi udara yang memadai membantu tiap vaksin mempertahankan suhu dengan konsisten. Kondisi penyimpanan vaksin terdapat jarak pada tiap vaksin, dan lemari es yang disertai dengan termometer dan vaksin heat sensitive seperti BCG diletakkan didekat cold pack. Hasil observasi di PKM E sama dengan PKM yang lainnya yaitu telah sesuai dengan pedoman penempatan jarak refrigerator dengan dinding belakang 10-15 cm. Pemantauan suhu yang dilakukan di PKM E juga telah dilakukan secara rutin oleh petugas penanggung jawab vaksin sebanyak dua kali sehari setiap pagi dan sore, dan dihari libur dilakukan oleh petugas yang bertugas di hari tersebut.

Pemantauan suhu vaksin bisa dilihat dari termometer dalam freezer atau termometer luar freezer. Tetapi dari semua observasi yang dilakukan, monitoring suhu dilihat dari termometer luar freezer untuk lebih mempermudah agar tidak membuka tutup freezer yang bisa merubah suhu vaksin dan untuk memperkecil kerusakan vaksin. Pemilihan vaksin yang akan digunakan di PKM E juga berdasarkan prinsip FEFO dengan mempertimbangkan kondisi VVM. Prinsip FEFO pada pengeluaran vaksin bergantung tanggal kadaluarsa vaksin, vaksin yang kadaluarsanya lebih dekat akan dikeluarkan terlebih dahulu. Prinsip VVM pada pengeluaran vaksin yaitu ketika suatu vaksin VVM berubah posisinya namun masih dapat digunakan akan dikeluarkan terlebih dahulu. Prinsip FIFO diberlakukan setelah prinsip FEFO. Selama melakukan observasi di kelima puskesmas kecamatan, menurut informasi petugas penanggungjawab vaksin, apabila ada vaksin yang telah rusak atau lewat masa kadaluarsanya dilaporkan kepada pihak manajemen puskesmas yang bekerjasama dengan pihak ketiga. Pihak ketiga adalah badan pengolahan limbah rumah sakit, puskesmas atau klinik. Biasanya petugas dari pihak ketiga minimal sebulan sekali datang ke puskesmas untuk mengambil limbah. Sebelum diserahkan ke pihak ketiga, tutup karet dan stiker vaksin dilepas dari vial vaksin tersebut sehingga hanya menyisakan vial tanpa stiker. Selanjutnya akan dilakukan pemusnahan oleh pihak ketiga. 
Tabel 1. Pengelolaan Rantai Dingin Puskesmas Kecamatan Jakarta Timur tahun 2019

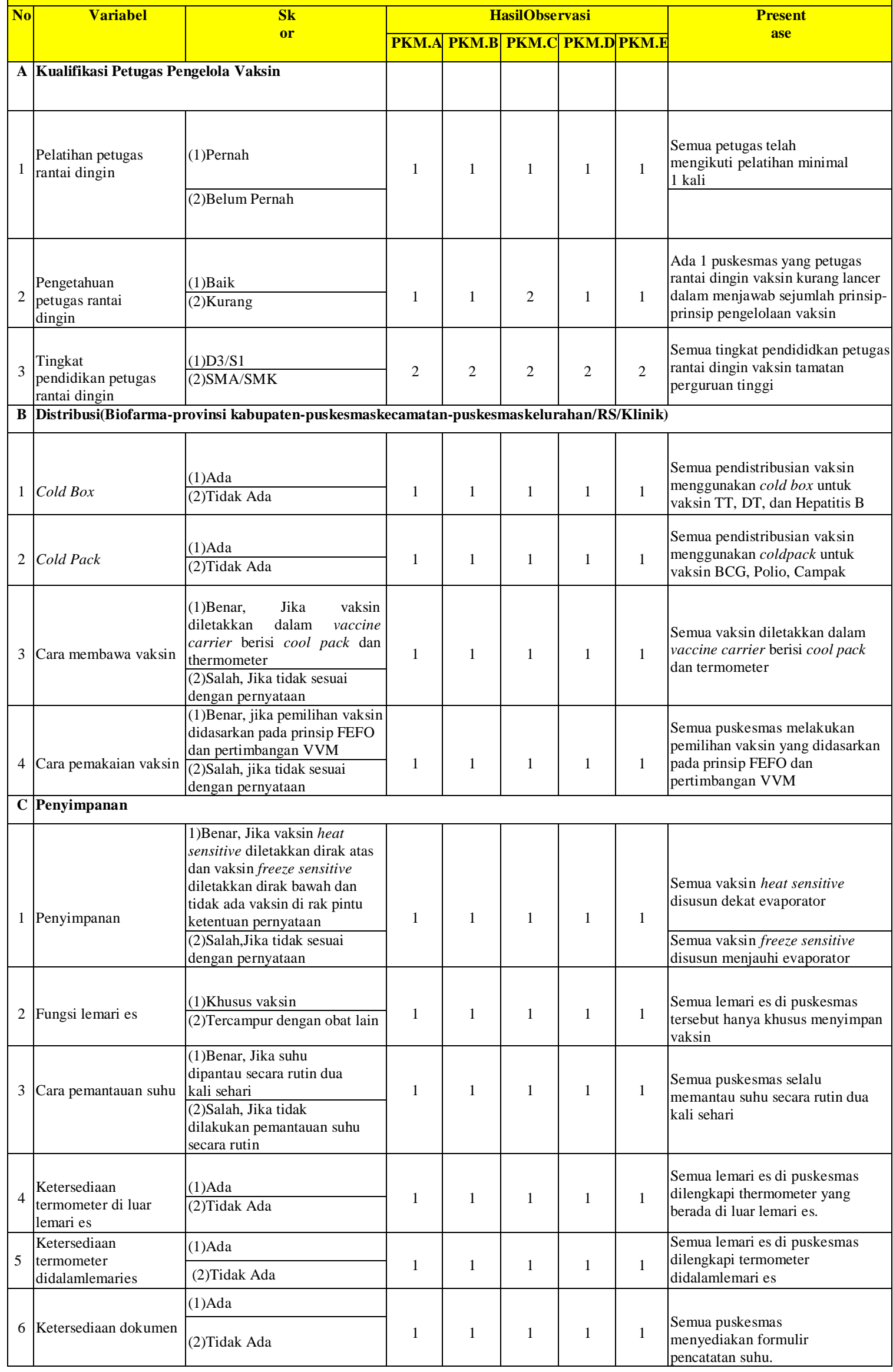




\begin{tabular}{|c|c|c|c|c|c|c|c|c|}
\hline \multirow[b]{2}{*}{7} & \multirow{2}{*}{$\begin{array}{l}\text { Ketersediaan } \\
\text { pedoman } \\
\text { pengelolaan vaksin }\end{array}$} & (1)Ada & & & & & & \\
\hline & & (2)Tidak Ada & 1 & 1 & 1 & 1 & 1 & $\begin{array}{l}\text { Semua puskesmas tersedia } \\
\text { Standard Operasional Procedure } \\
(\text { SOP) di masing-masing instansi }\end{array}$ \\
\hline
\end{tabular}

\section{KESIMPULAN}

Berdasarkan pedoman Vaccine Storage and Handling Toolkit(CDC 2014) menunjukkan bahwa sistem pengelolaan rantai dingin vaksin di lima puskesmas kecamatan di wilayah Jakarta Timur telah sesuai pedoman tersebut.

\section{DAFTAR PUSTAKA}

CDC (2019) 'Vaccine Storage and Handling Toolkit', Vaccine Storage and Handling Toolkit, (January), pp. 1-49. Available at: www.cdc.gov/vaccines/imz-managers/awardeeimz-websites.html.

Chiappin, S. et al. (2014) 'Center for Disease Control and Prevention (CDC): Storage and Handling of Lipids', Clinica Chimica Acta, 383(1-2), pp. 1-5. doi:

10.1016/j.cca.2007.04.011.

Debby Permatasari Iwan Dwiprahasto, 2018 (no date) 'Evaluasi Implementasi Managemen Rantai Dingin Vaksin dengan Viabilitas Vaksin di Suku Dinas Kesehatan Jakarta Timur dan jajarannya'.

Gebbie Prisiliya Lumentut, Nancy C. Pelealu, A. C. W. (2015) 'Evaluasi Penyimpanan dan Pendistribusian Vaksin dari Dinas Kesehatan Kota Manado Ke Puskesmas Tuminting, Puskemas Paniki Bawah dan Puskesmas Wenang', 4(3), pp. 9-15.

Kairul, K., Udiyono, A. and Saraswati, L. D. (2016) 'GAMBARAN PENGELOLAAN RANTAI DINGIN VAKSIN PROGRAM IMUNISASI DASAR (Studi di 12 Puskesmas Induk Kabupaten Sarolangun)', Jurnal Kesehatan Masyarakat Universitas Diponegoro, 4(4), pp. 417-423.

Knowledge, R. B. et al. (2013) 'Hubungan antara pengetahuan dan sikap pengelola vaksin dengan skor pengelolaan vaksin di daerah kasus difteri di jawa timur', 23(3), pp. 102-109.

Kristini, T. D. (2008) 'Faktor-faktor risiko kualitas pengelolaan vaksin program Imunisasi yang buruk di Unit Pelayanan Swasta (studi kasus di Kota Semarang)', pp. 1-176. Available at: http://eprints.undip.ac.id/18020/1/TRI_DEWI_KRISTINI.pdf.

Litalien, D. et al. (2009) 'No Titlelالزازب l', Bifurcations, 45(1), pp. 1-19. doi: 10.7202/1016404ar.

Magee, R. V. et al. (2017) 'No Titleانيئانجلا تاءارجال', ABA Journal, 102(4), pp. 24-25. doi: 10.1002/ejsp.2570.

Ministry of Health Indonesia (2013) 'Peraturan Menteri Kesehatan nomer 42 tahun 2013 tentang penyelenggaraan imunisasi’, (966), pp. 17-97.

Rahmah, N. and Lasmini, P. S. (2014) 'Artikel Penelitian Hubungan Karakteristik dan Tingkat Pengetahuan Petugas Imunisasi terhadap Praktik Penyimpanan dan Transportasi Vaksin Imunisasi di Tingkat Puskesmas Kota Padang Tahun', 4(3), pp. 917-924.

Ranuh, I. . G. et al. (2017) Pedoman imunisasi di Indonesia, Pedoman imunisasi di Indonesia. 
Utoro, G. A., Masria, S. and Trisnadi, S. (2017) 'Gambaran Penerapan Rantai Dingin Vaksin

Imunisasi Dasar di Purwakarta Tahun 2017', Prosiding Pendidikan Dokter, 2017(2), pp.

136-142. Available at: http://karyailmiah.unisba.ac.id/index.php/dokter/article/view/7487. 